NBER WORKING PAPER SERIES

PRIVATIZATION, INFORMATION AND INCENTIVES

David E. M. Sappington

Joseph E. Stiglitz

Working Paper No. 2196

NATIONAL BUREAU OF ECONOMIC RESEARCH

1050 Massachusetts Avenue

Cambridge, MA 02138

March 1987

This paper was written for the Conference on Privatization in the Public Sector at The University of Pennsylvania, September 19B6. The views expressed in this paper are not necessarily those of Beli Communications Research. Discussions with Michael Riordan were instrumental in formulating a number of the ideas in this paper. Comments by Janet Pack, Almarin Phillips, Dennis Yao and other conference participants are gratefully acknowledged. The research reported here is part of the NBER's research program in Taxation. Any opinions expressed are those of the authors and not those of the National Bureau of Economic Research. 


\title{
Privatization, Information and Incentives
}

\begin{abstract}
In this paper, the choice between public and private provision of goods and services is considered. In practice, both modes of operation involve significant delegation of authority, and thus appear quite similar in some respects. The argument here is that the main difference between the two modes concerns the transactions costs faced by the government when attempting to intervene in the delegated production activities. Such intervention is generally less costly under public ownership than under private ownership. The greater ease of intervention under public ownership can have its advantages; but the fact that a promise not to intervene is more credible under private production can also have beneficial incentive effects, The Fundamental Privatization Theorem (analogous to The Fundamental Theorem of Welfare Economics) is presented, providing conditions under which government production cannot improve upon private production. The restrictiveness of these conditions is evaluated.
\end{abstract}

David E. M. Sappington

Bell Communications Research

Morristown, NJ 07960
Joseph E. Stiglitz

Princeton University

Princeton, NJ 08544 


\section{INTRODUCTION.}

The issue of which goods and services should be produced publicly and which ones are better produced privately has long been a central concern of economists. The recent trend toward "privatization" reflects a judgment that previous "assignments" were incorrect - that some activities within the public sector might be carried out better within the private sector. In this paper, we provide a conceptual framework within which several of the central issues can be addressed. Our particular concern is with the roles played by incentives and imperfect information in the privatization decision.

Although the labels "public" and "private" may elicit images of very distinct modes of operation, many similarities exist between the everyday operations of public and private enterprise in practice. Both modes involve substantial delegation of responsibility. Neither Con jressmen nor minority shareholders directly control the daily activities of an enterprise that is, in principle, under their control. Instead, oversight of the firm's operation is delegated to a commission or board of directors. A chief executive officer or president is also endowed with considerable discretion to influence the firm's operations. There generally follow many additional layers of authority under both forms of ownership. The hierarchy of authority terminates in both cases with managers who use their precise knowledge of local conditions to make daily decisions that directly affect the Girm's performance. Thus, if one examines their everyday functioning, public enter prises and privately owned firms appear quite similar in many respects.

The important difference between public and private ownership, in our view, involves the residual rights of intervention. Under public enterprise, the government retains some authority to intervene directly in the delegated production arrangements and implement major policy changes when it is deemed necessary to do so. Under private ownership, special rights of intervention are afforded creditors (in the event of bankruptcy) and major financial interests (who can gather the resources necessiry to finance a takeover of the private firm); but the 
government's right to intervene is more limited tban under public ownership. ${ }^{1}$

Even in this dimension, however, the distinction between public and private ownership is not entirely clear cut. For example, under conditions of national emergency (sucb as war), the government bas intervened in the operations of private firms, diverting their resources to better serve the "social interest". Furtbermore, banks and other creditors often put pressure on government-owned firms in times of financial crisis. In addition, tbe government has been known to intervene in order to rescue private firms from bankruptcy.

What seems important to focus on, therefore, are the transactions costs associated witb intervention. Direct government intervention into delegated production arrangements generally involves smaller costs under public provision than under private provision. As we argue below, such ease of intervention can constitute botb a potential benefit and a potential cost of public provision; these benefits and costs must be carefully weighed against any other inherent advantages and disadvantages of public enterprise.

In fact, more tban just the "rights of intervention" are at issue. Also at issue are: (1) the incentives to intervene and not to intervene, and (2) the limitations on abilities to commit to intervene or not to intervene. Cboosing a mode of organization can be thought of as affecting the costs and benefits of intervention, and tbus as altering incentives to intervene, substituting in part for commitment abilities.

In the next section, we present a basic theorem concerning privatization. The theorem provides conditions under which all of the government's objectives can be attained by an appropriately designed auction of the rights to produce a given product or service. The theorem plays a role in the privatization issue much like the role played by the Fundamental Theorem of Welfare Economics more generally: it says that when certain conditions are satisfied, government involvement cannot improve upon the performance of the private market. An examination of the 
conditions of the theorem provides a checklist of "privatization failures" (analogous to "market failures"), i.e., reasons why privatization may not achieve the most desired outcome. Unfortunately, determining whether government production would remedy these failures is a more difficult matter. To answer that question, a theory of government behavior is needed. While we do not present such a theory, our general approach does offer some insight into the kinds of situations where government production is most likely to alleviate the problems associated with private production.

Though we focus in the next section on the choice between public and private enterprise, we point out in the following section that, in practice, the relevant choice of organizational mode is not always the "either/or" choice of public versus private provision. Institutional arrangements like regulation occupy intermediate positions in the continuum of ownership possibilities. Such institutions incorporate many of the desirable (and undesirable) features of both public and private enterprise.

\section{THE SCOPE FOR PUBLIC PRODUCTION.}

It is well known that for private goods (i.e., goods whose consumption by one individual precludes their consumption by anotber), private production can attain a Pareto efficient allocation of resources, provided certain conditions are satisfied. (These conditions are specified in the Fundamental Theorem of Welfare Economics and pertain to the production technology and to the dispersion of information in the economy.) If the distribution of income that results is not the desired distribution, then only limited government intervention - in the form of lumpsum redistributions - is called for. Government intervention is required, for instance, if there are externalities, natural monopolies ${ }^{2}$, or public goods. In the case of public goods (where consumption of the good by one person does not preclude consumption by others), the government must determine the amount of the good to be purchased if there is to be a Pareto- 
efficient level of consumption. Though there is agreement that some intervention is necessary in each of these cases, there is not agreement on the form that the intervention should take. In the present discussion, we focus on one aspect of that decision - private versus public production.

The government's objective in choosing among alternative forms of production are threefold. (1) Economic Efficiency: The government wishes to ensure that those who have a comparative advantage in production undertake it, and that the appropriate techniques of production and levels of effort are supplied. (2) Equity: The government desires to fulfill certain distributional objectives. (3) Rent Extraction: The government hopes to extract as much rent (i.e., profits) from producers as possible. (Note that concern over rent extraction can be viewed as a special case of the government's concern with rent distribution. Here, the distribution is between "consumers" and "firms".)

Our central theorem (which is an application of results in the "principal - agent" literature) ${ }^{3}$ provides conditions under which all of these objectives can be attained "perfectly" through an auction system whereby potential producers bid for the right to provide the good. This result requires two or more risk neutral firms (agents) who have symmetric beliefs about the least cost production technology. Actual costs are only learned by the chosen producer just prior to production. (For simplicity, assume the product is produced with increasing returns to scale, so industry costs are minimized with a single producer.) The government (principal) has a certain valuation, $\mathbf{v}$, of the level of output, $Q$, of the product or service in question. This valuation is given by $\mathrm{v}=\mathrm{V}(\mathrm{Q})$. Note that any distributional objectives can be reflected in $\mathrm{V}(\bullet)$ by explicitly including in the government's valuation function the levels of consumption of different groups within the population. These elements characterize what we will call "the ideal setting".

The following simple procedure ensures that the government attaing all of its objectives in the ideal setting: The government auctions of the right to receive payment for production, $P(\cdot)$, 
according to its valuation of output, i.e., $P(Q)=V(Q)$. In other words, the production decision is delegated entirely to the producer, and the producer is paid for his output an amount exactly equal to the value of that output to the government. The result of implementing a compensation scheme of this form is that the firm submitting the highest bid (and therefore chosen to be the producer) will subsequently select the production level most desired by the government, conditional on the realization of actual production costs. And with the risk neutral firms initially sharing symmetric beliefs about costs, the bidding procedure will guarantee that no rents accrue to the producer. Thus, the government can ensure the ideal outcome via delegation of production, even though it has no knowledge of the production technology. We refer to this result - that with the appropriately designed auction, public production cannot improve upon private production -- as the Fundamental Privatization Theorem. As noted above, we refer to the conditions under which the Theorem holds as the "ideal setting".

As simple and attractive as the auction procedure sounds, one might question the widespread concern over whether and how to delegate (privatize) provision of various government services. But we know of no major instance in which the procedure has been implemented. The reason may be that the ideal setting incorporates a number of features that do not necessarily characterize the settings germane to privatization discussions.

There are three main reasons why the ideal outcome described above will not generally be attainable in practice. First, there will often be difficulties in extracting rents from the chosen producer. Second, contracting costs and institutional restrictions on feasible contracts limit the government's flexibility in contract design. Third, problems with contract implementation are likely to arise. To illustrate these three broad categories of concern, we re-examine the ideal setting in some detail, pointing out the critical and often unrealistic features it incorporates. 
Imperfect Rent Acquisition.

Even if the government can select the producer with the lowest expected costs and induce the producer to operate at minimum realized cost, in practice the producer will often earn rents. Such rents generally arise when the potential producers are averse to risk, when competition for the right to produce is limited, and when the government has pertinent information not shared by potential producers. We examine these three issues in turn.

Risk Aversion. A critical feature of the ideal setting is that potential producers not be averse to risk. The assumption ensures that the government need not pay any risk premia to the firms, even though their knowledge of the production technology may be quite limited and, consequently, their final compensation quite uncertain.

When potential producers have better information about the technology of production and are more averse to risk than the government, an important tradeoff is introduced. Delegation of production is advantageous because production decisions are placed in the hands of individuals who are better informed (and thus better able to carry out production). On the other hand, risk premia must be paid to compensate producers for the risk they bear. To the extent that the government absorbs risk for private producers, more rents can be captured for the government. However, risk absorption by the government reduces the incentives for efficient performance by producers. And to the extent that the government forces private producers to absorb the risk, production may be undertaken not by the producer with the least expected costs, but by the producer with the least aversion to risk. (Of course, the costs of risk absorption are no less real than other costs.) Also note that if "the government" is more tolerant of risk than private producers, government production may be desirable: the extra rents that must be paid to the private sector when production takes place there may outweigh "the government's" cost disadvantage. 
Considerations of risk are clearly important in determining the choice of public versus private provision and in designing the auction in the event of privatization. (For example, cost sharing provisions of defense contracts reduce the compensation that the government must pay for risk absorption; but they also have well-documented efficiency costs. Furthermore, one of the arguments for royalty versus bonus bidding for oil and gas leases is that under royalty bidding, wherein a unit royalty fee is placed on extracted hydrocarbons, private firms absorb less risk.) But characterizing the extent and concentration of risk in the two settings is not straightforward. Under public provision, much risk is ultimately borne by the "owners" of the enterprise. Because the owners here are the entire populous, risk is widely diflused. Under private provision, the stock market may serve to diffuse much of the risk inherent in the operation. To the extent that it does, it is not apparent that the relative degrees of risk aversion for the principal and agent should be systematically higher under public or private enterprise. What is apparent, however, is that if risk is widely diffused, strong incentives for diligent performance will be lacking under both modes of operation. (What is particularly relevant for organizational performance is whether decision-makers bear the full brunt of the consequences of their decisions. To the extent that they do, they are likely to act in risk averse ways; to the extent that they don't, incentives will be blunted.)

The absence of good risk markets offers one exsmple where "market failures" impinge on the privatization deciaion. Another example occurs when the interest rate faced by a private producer exceeda that faced by the government. This market imperfection, like the absence of risk markets, can be explained in terms of imperfect information and transactions costs. The possibility of default by private producers raises their costs of capital; and a real difference exists in the "coats of finance" under public and private ownership because default risks are borne differently. The deviation between public and private rates of interest in the case of oil leases is 
sufficiently important that the government obtains only a small Iraction of the total social rents under bonus bidding. Similar considerations would argue that the government should own, rather than lease, its buildings (unlese strong countervailing managerial advantages to private ownership can be established). In effect, in each of these instances the government is borrowing indirectly from the private sector, but paying far higher rates than it does on Treasury bills.

Limited Competition. Another reason why rents may acerue to the selected producer is the absence of sufficient competition at the bidding stage. In the ideal setting, a number of potential producers are symmetrically informed about potential production costs. When there are very lew competitors, each with a different assessment of likely costs, then the winning bidder will generally receive rents. And to limit these rents, it is usually optimal to induce inefficient production ex post, even if bidders are risk neutral. Intuitively, the distortions arise because they render the "object" being auctioned more similar to the various bidders, thereby lostering more competitive bidding. Defense and oil again provide salient examples. In both cases, competition is generally limited. (In recent auctions for oil and gas tracts, the average number of bidders for each tract has been less than two.) Some have argued for royalty bidding in preference to bonus bidding, even though the royalties may distort the pattern of hydrocarbon extraction. The argument is that the gain in government revenues from bidding that result under royalty bidding more than offsets the losses in efficiency that may arise in the form of too little extraction. ${ }^{5}$

A related "distortion" is that it will be optimal for the government to undertake production in some instances where its expected costs exceed those of the most efficient producer. The threat of losing the right to produce altogether induces potential producers to bid for that right more aggressively.

In some cases, only one firm with the technological capability is available to carry out production. This is particularly likely to be the case when the technology is new and experience 
in the marketplace is a critical element in keeping production costs low. Hence, if one firm has been the sole producer for a period of time, that firm may well have a significant advantage over other potential producers. When there is effectively only one serious bidder, the firm can extract rents from the government. And with only a single firm producing a unique product, there are no natural benchmarks against which performance can be compared. Thus, with no ex ante or ex post competition, the problems of control and rent extraction become very difficult ones. But note that under these circumstances government production faces a similar problem: in cases that lack a natural comparison of efficiency, it will be difficult to ascertain whether government production is efficient. Precisely these kinds of circumstances provide government bureaucrats with the opportunity to increase the size of their organization. (See William Niskanen, "Bureaucrats and Politicians", Journal of Law and Economics, 18(1975): 617-643.)

Of course, the number of potential and actual producers in an industry need not be exogenous parameters from the government's point of view. By intentionally subcontracting production to more than one existing firm, the government can ensure competition in present production and in future related production. Furthermore, the government can actually create its own firms or subsidize the formation of new firms. In these ways, the government can infiuence directly the extent of competition in relevant markets, but obviously at a cost.

Informed Principal. Another special feature of the ideal setting concerns the distribution of information between the government (or, more generally, the "principal") and potential producers (or "agents"). In the ideal setting, the agents have better information than the principal. When the principal's information (about, say, the inherent difficulties of the productive task in question) is better than that of potential producers, however, the nature of the incentive scheme designed by the principal may signal some of his private knowledge. To conceal this information (rather than reveal, for example, that the task is really quite difficult and likely 
to require large investments of effort and capital to be completed successfully), the principal may deviate from the simple scheme described above. Such a deviation may result in a different mode of production or a different distribution of rents.

Oil lease sales again provide an example. The government calculates the value of a lease on the basis of the information it has. It then leases the tract only if the bid is sufficiently high relative to this estimate. Note that if the private sector believed the government to be well informed and able to set a minimum bid in the auction equal to the expected value of the oil, then bidders would believe that they can only win the auction if they bid too much. Hence, they will not bid at all. More generally, the fact that the government has some superior information can have adverse (though perhaps not quite so extreme) effects on bidding behavior.

In general, whenever the principal's superior knowledge is difficult to convey by means other than direct interaction with the producer during the production process, the chosen mode of organization may be the one that best facilitates such ongoing communication. Whether there are important instances where this concern enters the decision about whether to "privatize" production remains to be established.

\section{Contracting Costs and Limitations.}

We now examine how institutional restrictions on contracts and costs of writing contracts can complicate the ideal setting. The institutional restrictions include limits on the liability of producers and limited commitment on the part of the government. Contracting costs arise, in part, from the difficulty in anticipating all possible contingencies.

Limits of Liability. In the ideal setting, the producer may conceivably make large losses. The only requirement imposed is that producers expect to break even when they submit their bids. With imperfect information about costs, ex ante cost estimates may be more optimistic 
than actual cost realizations. Under such realizations, the producer will prefer, ex post, that he had never entered into any agreement with the government. And if there are bounds on the loses a contractor can he forced to bear (due, say, to bankruptcy laws, political considerations, etc.), the contractor may renege on the contract rather than provide the promised services. In such circumstances, the ideal outcome for the government is no longer ensured.

Consider the implications of liability restrictions for the provision of national security. The social losses that might arise from failure to provide adequate defense could be astronomical -. far in excess of any "bond" that a private producer could conceivably post to ensure performance. Thus, with feasible penalties for failure that are dwarfed by the social losses that would result from failure, private producers cannot be induced through monetary means to invest the appropriate level of effort to prevent failure.

This does not imply, however, that public provision is necessarily the superior mode of operation. The penalties that can be imposed on public officials when a failure (or, more generally, a deterioration of service) occurs are not unbounded. And even under, public ownership, many facets of production are commonly subcontracted to private fims. Thus, the debilitating effects of limited liability restrictions on performance incentives arise under both public and private provision of services.

Lack of Commitment. One interpretation of liability limitations is that the producer is unable to commit himself to carry out the terms of a contract to which he has initially agreed. Commitment ahilities on the part of the government are also essential for the delegation scheme described ahove to be feasible.

To achieve its most preferred outcome through the suction procedure described above, the government must he able to credibly commit itself to compensate the producer as promised. In 
particular, the government must be able to convince potential producers that no renegotiation of the contract will be carried out once a producer is selected, and that payments made to the producer $(P(Q))$ will equal the value of the output to the government (V(Q)). Thus, even though the producer may end up with extremely large profits, the government must be able to credibly promise not to tax away these gains; similarly, the government cannot subsidize losses ex post that were agreed to be a possibility ex ante. Absent such commitment, the producer knows that, in fact, $V(Q)$ is not the relevant compensation schedule; consequently, the government's most preferred outcome is not assured.

The government's commitment abilities may well vary according to the chosen mode of organization. Private ownership generally puts some distance between the government and the producer, thereby making more credible a promise not to use public funds to subsidize losses incurred by the producer. Of course, there are instances where public funds have been put at risk to rescue private firms from bankruptey. The Chrysler Corporation "bail-out" program is one example in recent U.S. history. Nevertheless, the transactions costs (which included public hearings, careful legal scrutiny, etc.) of such intervention were substantial. Promises not to subsidize the losses of public enterprises are generally more difficult to keep. The French experience with the supersonic transport airplane is but one example to this effect. Using the terminology employed in the introduction, the issue here concerns the transactions costs of intervention. Public ownership tends to reduce the costs of government intervention, and thus makes such intervention more likely, ceteris paribus.

Contracting Costs. To this point, we have assumed that it is costless to write down all possible contingencies and agree on payment and performance for all such events. In fact, contracts may be very costly to negotiate, and many contingencies are virtually impossible to foresee. This applies particularly when the production technology is very complex and subject to 
frequent change, as in the defense sector for example. Recognizing this fact introduces the possibility that complete decentralization may not be so desirable; instead, continual communication and renegotiation between "principal" and "agent" may be mutually desirable in order to deal with unforeseen contingencies. ${ }^{7}$

The nature of the ex post interaction is, again, affected by a whole set of production decisions. If the government chooses a single supplier, then informational asymmetries will be created between that supplier and other potential suppliers. In the presence of perfect capital markets and with risk neutrality, the expected value of these additional rents from ex post renegotiation will be reflected in initial bids. But even under these extreme assumptions, economic efficiency may not be assured: the firm bidding the most may not be the least cost producer, but the firm with the greatest ex post bargaining ability; and the ex post bargains themselves may not be efficient. ${ }^{8}$

Once the possibility of continued interaction is introduced, the issue of which mode of organization best facilitates this interaction in a constructive manner arises. A critical question concerns which parties are optimally included in the ongoing interaction. In particular, should Congress have oversight responsibilities, or should they be left to the Judiciary? And should the public have any direct say in matters? Permitting the public some continuing direct influence on the producer's activities may have the effect of undermining any authority or commitment powers of the Congress. As noted above, limiting its commitment powers can reduce the ability of Congress to effect the public's most desired outcome. Thus, this effect must be weighed against the beneficial role that direct access by the public can play in monitoring the activities of both Congress and producers.

Unknown Benefits. A related observation is that it is not a trivial exercise for the principal (government) to specify completely its preferences. In other words, the benefit function 
$V(Q)$ may not even be known to the principal. This could occur because $V(Q)$ may be an aggregation of the preferences of many "principals" that is difficult to specify and communicate through the political system.' Another reason why V(Q) may not be known could simply be that the commodity in question is a new one whose attributes change rapidly with developing technology. For whatever reason, if the benefit funetion $V(Q)$ is not perfectly known, then the simple and complete decentralization effected in the ideal setting will not be feasible, and efficient production cannot be guaranteed by the procedure.

In many cases, the government may delegate to the private producer the right to determine the payoff function, $P(Q)$, within a certain domain. That is, the firm is afforded limited freedom in setting a pricing structure. Although the private firms may indeed be better informed about consumers' demand functions, awarding them pricing freedom introduces a potential source of inefficiency: the winning bidder may not be the most efficient producer, but the firm that knows best how to price discriminate. Thus, only in certain limiting cases will the payoff function facing the firm correspond to the one the government would have implemented if it shared the firm's private information.

The cause of the government's limited knowledge of V(Q) will influence the correct policy preseription. To illustrate, suppose members of the public know their individual preferences, but Congress does not. In this case, good reasons exist to facilitate direct interaction between producers and the public, limiting the role of Congress. Hence, it may well be left to private enterprise to discern and satisfy the desires of the public. This is particularly likely to be true when competition among producers is feasible and the commodity in question is "common" -. and therefore readily understood and evaluated by consumers. In this case, careful supervision of producers by the government to protect consumers is not necessary. When consumers can monitor the performance of producers easily and have alternative sources to turn to if they are 
not satisfied with a particular supplier (i.e., if sufficient ex post competition exists), consumers can readily discipline a producer themselves to ensure that the commodities that maximize their benefit function are produced; they need not rely on the government to do so.

Of course, the privatization debate focuses on industries where scale economies are such that few producers exist or the commodity in question is a public good. In the case of public goods, a free-rider problem arises in monitoring performance (because no one individual has sufficient incentive to monitor, even though the total social benefits from monitoring outweigh the associated costs). With scale economies, there is an information problem due to the absence of alternative suppliers. As a result, consumers have difficulty judging and evaluating performance. Thus, monitoring by consumers with the implicit threat of switching suppliers should not be expected to work well in these settings.

If the limited knowledge of the government's benefit function $V(Q)$ arises because consumers do not know their own preferences, then it may be important for the government to monitor directly the performance of producers, ensuring that they act in the interests of consumers. Consequently, optimal design of a governing structure may entail relatively small transactions costs of government intervention into the activities of subcontractors. To illustrate, consider the case of education. Exactly what constitutes "education" is not readily specified, measured, or contracted for. Furthermore, individuals often are not certain exactly how they value education; and what constitutes an adequate education is aubject to continual change. For all these reasons, facilitating ongoing government supervision via the public provision of education may be desirable.

\section{Problem in Implementing Contracts.}

We now consider the complications that arise in implementing contracts. Four issues are 
addressed here: problems in measuring performance, limits on the ability to capitalize the enterprise, problems with multiple products, and the difficulties introduced by complicated hierarchies of control.

Imperfect Mecostrement. In the ideal setting, the "output" of the producer can be observed perfectly and costlessly by all parties. In practice, performance has many components, and some are difficult to measure accurately. For example, all aspects of the quality of a service are hard to quantify, particularly when the same product may be valued and perceived differently by different consumers.

When the performance of producers cannot be readily monitored, a serious control problem may arise under both public and private provision. Which mode is best suited to deal with the problem is an important question for future research. We note only that the remarks made above about the consequences of imperfect knowledge of the benefit function $V(Q)$ apply here.

Capitalization Considerations. In the ideal setting, no separation existed between the ownership and the management of the productive enterprise. Furthermore, the owner/manager of the firm was able to buy and sell assets. Profits, therefore, were readily consumed by transferring net cash flows from the enterprise to the owner/manager. This feature of the incentive scheme allowed the preferences of the relevant parties to be perfectly aligned, and motivational issues were readily resolved. In practice, such capitalization is not possible; managers of both publicly and privately owned firms cannot be rewarded according to the increment in (the present discounted value of the) profits that their activities generate. Knowing this, managers will take their rents in other forms. In public enterprise, rents are often awarded in the form of political patronage. In both public and private enterprise, executives receive compensation in the form of job-related perquisites. While such forms of compensation may help 
to motivate executives and managers, obvious inefficiencies arise. For example, when compengation is not perfectly correlated with profits, executives will be slow to reinvest any excess revenues with the intent of generating future profit. Ingtead, the firm will be "bled" via rent extraction in the aforementioned forms; hence the need for ongoing supervision of activities.

Thus, once there is delegation of respongibility and an effective separation of ownership and management, there is dissolution of performance incentives under both public and private ownership. Whether the problem is more severe under one mode of organization or the other remains an open question. The answer depends, in part, on how well performance can be monitored, how effective is competition, etc. in the two modes.

Aggregation of Products. In the ideal setting, a single unidimensional product was produced by a single firm. In effect, the decisions concerning the provision of this product were isolated from all others. In practice, the delegation decision is not so simple.

When there are multiple products whose provision must be secured, global knowledge of the least costly means of producing every conceivable output vector must be known to at least two risk neutral contractors in order to ensure the achievement of the government's most preferred outcome. Such knowledge is unlikely in practice. And absent such global knowledge, the government will be forced to delineate boundaries between productive activities, despite being poorly informed about the best way to do so. As a result, inefficiencies will generally arise. (Indeed, the only way to avoid these problems is for the government to engage in bidding over the entire economy.)

To illustrate the problem, suppose the government wishes to procure two distinct and fairly complex products. The government is aware that the products are quite intricate, but it is not fully aware of the production complementarities between them. (Concerns of this sort seem 
particularly relevant in the telecommunications industry.) To ensure efficient procurement, the government establishes two commissions, one to oversee both the acquisition and distribution of each product. Even if, as in the ideal setting, each commission secures the maximum possible surplus for consumerg within its assigned sector, it is not certain that aggregate surplus will be maximized. Both design and production complementarities will generally be overlooked by the identified procedure; yet the procedure is not an unreasonable one in light of the government's limited knowledge of global production technologies. ${ }^{10}$

A related problem involves joint products. It may not be possible to produce one product (e.g., military equipment) without simultaneously producing another (e.g., knowledge of confidential military information). Thus, to control the distribution of one product (information), it may be necessary to compromise on the mode of producing the other product (equipment).

Hierarchical Control / Multiple Principals. In the ideal setting, the preferences of the principal, "the government", will essentially dictate social welfare. The single principal also manages directly the procurement of the commodity in question. In practice, hierarchical control poses a much more difficult problem. The difficulty stems from at least three sources. First, there are many principals whose preferences may not coincide. Second, control over delegated production arrangements, design of compensation schedules, and other such matters are all delegated to a party (e.g., Congress) that may be partially motivated by self interest. In other words, the "principal" of the ideal setting is really an "agent" of a group of principals; this "delegated principal's" valuation of ultimate performance may reflect his own preferences as well a (or instead of) those of the principals he is supposed to serve. Third, control authority is generally delegated to more than one party. And with multiple delegated principals, each having different mandates and each having control over different policy instruments, the outcome will 
generally not be Pareto-efficient. ${ }^{11}$

With multiple principals, the obvious problem of aggregation exists. Unless the principals have identical preferences, it will be a difficult task simply to aggregate preferences into a consistent social welfare function like $V(Q)$. More commonly, each principal has control over a particular part of the payoff function. Thus, if there are several commodities, the principal might set $P_{i}\left(Q_{i}\right)$ as the payof function for the $i$ th commodity. The total payoff function is then the sum of these individual payoff functions, and may have little resemblance to any consistent social welfare function $V(Q)$. Furthermore, even if this function could be constructed and conveyed to the delegated principal, there is no guarantee that this individual would act selflessly to maximize the function. When the actions of the delegated principal are not readily monitored, and when the private interests of the delegated principal do not coincide with the "social interest" (so that difficulties in controlling both the delegated principal and the producer arise), perfect internalization of the social preferences will not be achieved. ${ }^{12}$

When we put names on the relevant actors, an additional related complication becomes apparent. Along with whatever other powers that the public (i.e., the principals) delegates to Congress (the delegated principal), Congress always has the nearly unlimited power to tax the public. And Congress cannot credibly commit itself not to exercise this power. Consequently, the public may wish to put restrictions on the subcontracting arrangements that Congress can fashion. For example, salary limits and restrictions on profits to subcontractors may be imposed, as might restrictions on the types of projects that can be undertaken.

Obviously, such restrictions can have deleterious effects on incentives and hence on performance. Whether the social losses from such effects outweigh the potential gains of restricting delegated production arrangements seems likely to depend on the nature of the task in question. If the task is fairly routine and well understood, and if the variance in performance is 
small given adequate effort by the producer, restrictions on compensation will generally not compromise performance seriously. (The task of garbage collection comes to mind in this regard.) However, for tasks that are inherently more complex and that require creative and diligent effort by experts to enhance the probability of "success" of a risky venture (such as research and development), the undesirahle effects of restrictions on compensation to contractors may he quite pronounced. When prospective personal gains are slight, the most qualified contractors may not be attracted. And those contractors that are attracted may have little incentive to put forth effort if rewards are not commensurate with performance.

\section{MIXD MODES OF ORGANIZATION.}

The preceding discussion focused on the dichotomy of public versus private provision of services. In fact, the choice need not be an "either/or" choice. Some components of a service can be provided publiely and others privately. And there are methods of control such as regulation that are intermediate hetween public and private ownership in terms of the associated transactions costs of government intervention. In this section, we comment very briefly on the nature and role of these mixed modes of operation.

To begin, we note that the production process has many stages. Raw materials must he acquired, intermediate products manufactured, and the final product delivered to consumers. In practice, all of these activities need not he carried out by the government, even under "public enterprise". To illustrate, consider the provision of national security. Although the final product is delivered to consumers hy the government, many inputs (e.g., weapons and equipment) are secured from private producers. Thus, the distinction hetween public and private provision of a service is not entirely clear-cut. The relevant distinetion may be where private enterprise ends and public control hegins in the sequence of productive activities that comprise a service. 
Furthermore, even when the provision of a commodity is carried out entirely in the private sector, government influence is seldom altogether absent. For instance, legislation affecting the content and distribution of products is commonplace. In addition, members of the legislative and executive branches of government have been known to "jawbone" private industry in an attempt to influence its behavior.

The distinction between public and private provision becomes even more hazy when one recognizes that some modes of organization incorporate features of both public and private provision. One such mode is regulation. Firms that operate in regulated industries (such as utilities) are generally privately owned. Yet regulators, who are agents of the government, closely scrutinize their activities, and control the return on their investments.

In a sense, the auctions that we analyzed in the previous section can be thought of as auctions to become a regulated firm, where the payoffs to the firm are delineated by a predetermined valuation function. Yet important differences exist between the typical regulated industry and the ideal setting described above. (a) In many cases, there is no auction for the right to provide a particular service (e.g., cable television). (b) The regulator seldom compensates the firm according to the social valuation, $V(Q)$, of its activities. Rather, restrictions are imposed on pricing functions, on allowed rates of return, and on admissible costs. (c) While in our model there is a once and for all determination of both the franchisee and the compensation function $(V(Q)$ can be interpreted as a dated vector of outputs), in regulated industries the terms of the relationship are reviewed and changed periodically.

Still, a rationale for regulation can be surmised from the considerations outlined above. Competition is often absent or limited in regulated industries due to economies of scale in production. Thus, one role of the regulator is to provide ongoing monitoring of the firm's performance. Regulated firms are also generally characterized by complicated production 
technologies, so that the capabilities of a producer and the risks inherent in production are difficult to discern. A second role of the regulator, therefore, involves gathering information that can inform policy decisions and limit the rents of the firm. In doing so, the regulator (if properly motivated) develops the expertise necessary to direct activities in the best interests of his constituents. With less complicated technologies, the need for such an expert would be less pronounced. The key point here is that regulation lowers the transactions costs of intervention by a particular government agent (i.e., the informed regulator) relative to unregulated private ownership.

One aspect of the complex production technology in regulated industries is the specialized assets employed in production. Because these assets have limited alternative use, they are prone to expropriation once installed. Consequently, to attract the assets initially, the government must be able to credibly commit itself not to unfairly exploit the owners of these assets once the assets are in place. The institution of regulation may help to provide such commitment ability. The requirement that regulated firms be awarded a "fair rate of return" on invested capital does, at a minimum, raise the transactions costs of expropriating the firm and its shareholders. However, the matter is not entirely clear cut. It is not impossible for the assets of a regulated firm to be expropriated. The very fact that regulators are endowed with the power to establish prices de facto gives them significant expropriation powers.

One other obvious role for regulation is to facilitate risk sharing in a manner that does not eliminate incentives for efficient performance. By defining the rate base on which a "fair" return is allowed, the regulator can penalize the firm for unfavorable outcomes that were due to its own shortcomings, while at the same time ensuring that consumers share some of the burden of unfavorable events that could not have been foreseen and avoided. Of course, such discretion in defining the rate base also renders expropriation a more real possibility. ${ }^{13}$ 


\section{SUMMARY AND CONCLUSIONS.}

We have outlined some of the important consider ations in the choice between public and private provision of a commodity. We focused on the special concerns introduced by imperfect information about the productive environment. We identified an ideal setting in which privatization is the natural mode of organization. And we outlined a variety of ways in which real settings differ from the ideal one, noting the implications for the privatization issue.

Important similarities between public and private provision were also identified. Both modes, for example, are characterized by substantial delegation of authority. The delegation is a natura] response to the problems posed by imperfect information -- problems which arise under both forms of organization. What distinguishes the modes, in our opinion, are the differences in the transactions costs of intervention into delegated production relationships. Public enterprise generally facilitates intervention by "the government", while intervention is more difficult under private enterprise. The difference, however, is only a matter of degree in practice.

In choosing between public and private provision, it is important to consider both the expected benefits and the costs of intervention, and the probability that intervention will occur. Two important elements of this calculation include the complexity of the task under consideration and the need for rapid adaptation to unforeseen contingencies. When the task is particularly novel and complex, unforeseen contingencies are likely to arise. And if rapid adaptation to these events is crucial (as in the case of national defense, for example), ease of intervention to redirect activities and to limit the duration of renegotiation may be relatively important; under such circumstances, public provision is more likely to be the preferred mode of organization.

Of course, when the use of intervention is facilitated, its abuse is simultaneously made more difficult to control, and ineffieiencies will result. To illustrate, managers of public enterprises 
may have insufficient incentive to control costs, knowing that the government is likely to provide subsidies to offset any cost overruns.

In concluding, we wish to emphasize that neither public nor private provision can fully resolve the difficult incentive problems that arise when considerations of imperfect information result in delegation of authority. The choice between modes of organization simply defines the transactions costs of future intervention into these delegated relationships, and thereby influences the likelihood of such intervention. 


\section{FOOTNOTES}

1. Transactions costs of intervention are obviously related to residual rights of control. For more on such rights, see Sanford Grossman and Oliver Hart, "The Costs and Benefits of Ownership: A Theory of Vertical and Lateral Integration", Journal of Political Economy, 94(1986): 691-719.

2. The goods produced by natural monopolies we consider include both pure public goods like defense and publicly provided private goods like education. For a discussion of the reasons for public provision of such goods, see Joseph Stiglitz, The Economics of the Public Sector, (New York: W.W.Norton, 1986).

3. Some important early contributions to this literature, which is concerned with the issues of delegation and control, are: Stephen Ross, "The Economic Theory of Agency: The Principal's Problem", American Economic Review, 63(1973): 134-139; and Joseph Stiglitz, "Risk Sharing and Incentives in Sharecropping", Review of Economic Studies, 41(1974): 219-256.

4. This observation is recorded in Martin Loeb and Wesley Magat, "A Decentralized Method for Utility Regulation", Journal of Law and Economics, 22(1979): 399-404. The analysis abstracts from such complications as collusion among bidders.

5. For evidence of the potential gains under from royalty bidding, see Douglas Reece, "An Analysis of Alternative Bidding Schemes for Leasing Offshore Oil", Bell Journal of Economics, 10(1979): 659-669. For a formal model of this phenomenon, see Michael Riordan and David Sappington, "Awarding Monopoly Franchises", Stanford University discussion paper, Revised September 1986.

6. This conclusion is a straightforward extension of the work of M. Riordan and D. Sappington [1986]. The explanation for the conclusion is analogous to the explanation of why an 
auctioneer will generally establish a minimum bid in excess of his valuation of the object. (See John Riley and William Samuelson, "Optimal Auctions", American Economic Review, 71(1981): 381-392.) Similar intuition drives the finding that placing production with a more costly second source can comprise part of an efficient procurement mechanism. (See, for example: James Anton and Dennis Yao, "Second Sourcing and the Experience Curve: Price Competition in Defense Procurement", Rand Journal of Economies, 18(1987): F or theoming; and Joel Demski, David Sappington, and Pablo Spiller, "Managing Supplier Switching", Rand Journal of Economies, 18(1987): Forthcoming.)

7. These arguments are essentially those of Oliver Williamson, Markets and Hierarchies: Analysis and Antitrust Implleations, (New York: The Free Press, 1975).

8. For some thoughts on this issue, see, for example, Alvin Roth, Game Theoretic Models of Bargaining, (London: Cambridge University Press, 1987).

9. These are standard problems of aggregation and preference revelation that are emphasized in the social choice literature. See, for example, K. Arrow, Social Choice and Individual'Values, (New York: John Wiley and Sons, 1951).

10. For additional thoughts on this issue, see David Sappington and Joseph Stiglitz, "Information and Regulation", in E. Bailey (ed.), Public Regulation: New Perspectives on Institutions and Policies, (New York: The Free Press, 1987).

11. For a formal analysis of this issue in a regulatory context, see David Baron, "Noncooperative Regulation of a Nonlocalized Externality", Rand Journal of Economics, 16(1985): 553-568. For a more general analysis, see Richard Arnott and Joseph Stiglitz, "The Welfare Economics of Moral Hazard", Princeton University discussion paper, 1985. 